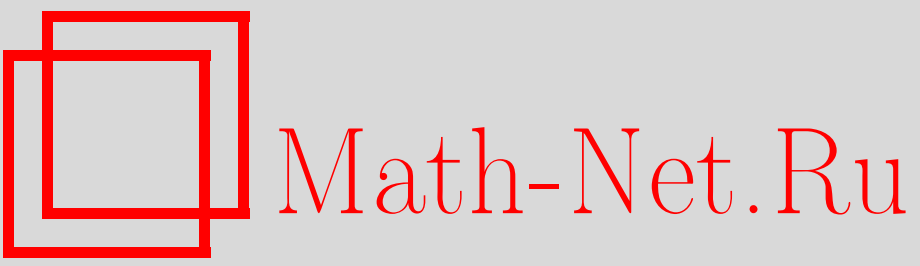

М. Г. Романенко, Г. В. Шагрова, В. И. Дроздова, Система компьютерного моделирования колебаний намагничивающихся микрокапель с учетом зависимостей межфазного натяжения от напряженности внешнего магнитного поля, Итоги науки и техн. Сер. Соврем. мат. и ее прил. Темат. обз., 2019, том 166, 57-65

DOI: https://doi.org/10.36535/0233-6723-2019-166-57-65

Использование Общероссийского математического портала Math-Net.Ru подразумевает, что вы прочитали и согласны с пользовательским соглашением

http://www. mathnet.ru/rus/agreement

Параметры загрузки:

IP: 34.239 .49 .27

26 апреля 2023 г., 15:48:23 


\title{
СИСТЕМА КОМПЬЮТЕРНОГО МОДЕЛИРОВАНИЯ КОЛЕБАНИЙ НАМАГНИЧИВАЮЩИХСЯ МИКРОКАПЕЛЬ С УЧЕТОМ ЗАВИСИМОСТЕЙ МЕЖФАЗНОГО НАТЯЖЕНИЯ ОТ НАПРЯЖЕННОСТИ ВНЕШНЕГО МАГНИТНОГО ПОЛЯ
}

(C) 2019 г. $\quad$ М. Г. РОМАНЕНКО, Г. В. ШАГРОВА, В. И. ДРОЗДОВА

\begin{abstract}
АннотАция. Разработана система компьютерного моделирования вынужденных колебаний намагничивающиеся микрокапель в переменном магнитном поле с учетом зависимостей межфазного натяжения от напряженности внешнего магнитного поля, полученных по данным натурного эксперимента. Результаты вычислительного эксперимента позволяют выявить особенности деформации микрокапель в магнитных полях с ростом напряженности магнитного поля.
\end{abstract}

Ключевые слова: намагничивающиеся микрокапли, колебания микрокапель, система компьютерного моделирования, магнитное поле.

\section{COMPUTER SIMULATION SYSTEM}

FOR OSCILLATIONS OF MAGNETIZABLE MICRODROPLETS

\section{TAKING INTO ACCOUNT THE DEPENDENCY}

OF THE INTERFACIAL TENSION

\section{ON THE STRENGTH OF AN EXTERNAL MAGNETIC FIELD}

\author{
(c) 2019 M. G. ROMANENKO, G. V. SHAGROVA, V. I. DROZDOVA
}

\begin{abstract}
We present a computer system for simulation of forced vibrations of magnetized microdroplets in alternating magnetic fields taking into account the dependence of the interfacial tension on the external magnetic field obtained from an experiment. Results of computing experiments allow one to identify features of deformation of microdroplets in increasing magnetic fields .
\end{abstract}

Keywords and phrases: magnetizable microdroplets, oscillations of microdroplets, computer simulation system, magnetic field.

AMS Subject Classification: 97M50; 68-04

\section{1. ВВЕДЕНИЕ}

В настоящее время использование современных технологий компьютерного моделирования, программных и аппаратных средств вычислительной техники не только позволяет осуществлять бесконтактное определение физических характеристик жидкостей на основе регистрации параметров колебаний их капель, но и может служить основой для автоматизации измерений в режиме реального времени. При этом выбор математических моделей, методов вычислений и техники 
проведения измерений зависит как от размеров капель, так и от их физических характеристик, которые могут изменяться под действием параметров внешней среды.

Начало исследованиям колебаний капель реальных жидкостей с учетом их вязкости под действием сил различной природы положила сформулированная Рэлеем классическая задача о малых свободных колебаниях капли идеальной жидкости (см. [17]), что привело к развитию нового направления в технике измерений, в частности, вязкости и межфазного натяжения капель жидкостей по параметрам их колебаний. Однако методы определения вязкости и межфазного натяжения капель жидкостей по их колебаниям не являются универсальными, так как математические модели и методы вычислений, разработанные для капель аэрозолей размером $<10$ мкм (см. [24]), капель диэлектриков (см. [6,13,14]), жидких металлов (см. [26]), заряженных (см. [10]) и намагничивающихся капель (см. $[3,7,8]$ ) существенно отличаются друг от друга. Отличается также и техника измерений, например, на основе применения печей для получения капель расплавленного металла, микроскопов или голографических методов для микроскопических капель. Тем не менее, часто единственно возможным методом бесконтактного определения физических характеристик жидкостей является метод, основанный на колебаниях капель исследуемой жидкости. Бесконтактное определение параметров магнитных жидкостей, которые находят широкое применение в различных технических устройствах и технологических процессах, контрольноизмерительных системах и в качестве магниточувствительных сред для исследования магнитных полей рассеяния намагничивающихся микроскопических объектов сложной формы (см. [21]) представляет как практический, так и научный интерес. Под действием различных факторов в магнитных жидкостях могут образовываться микрокапли (микрокапельные агрегаты), магнитная проницаемость $\mu_{i}$ которых $\left(\mu_{i}>20\right)$ на порядок выше, чем магнитная проницаемость $\mu_{e}$ окружающей их жидкости (см. $[4,23,25])$. Такие агрегаты могут использоваться в качестве датчиков магнитного поля (см. $[1,2])$, поэтому представляет интерес исследование их устойчивости к изменениям внешних параметров среды.

Так, изменение концентрации магнитных частиц на границе раздела поляризующихся и намагничивающихся жидкостей под действием внешнего магнитного поля может оказывать существенное влияние на межфазное натяжение (см. $[11,18])$ и устойчивость границ раздела намагничивающихся сред с различными магнитными свойствами. Исследованию влияния напряженности магнитного поля на межфазное натяжение посвящено большое количество работ, результаты которых носят противоречивый характер. Так в $[5,9,18]$ представлены результаты, позволяющие сделать вывод о зависимости коэффициента межфазного натяжения от ориентации магнитного поля относительно межфазной границы. В [19,22] проведено сравнение результатов магнитных измерений и экспериментальных данных, полученных в натурном эксперименте по гидростатике капель магнитной жидкости. В [19] сделан вывод о том, что поверхностное натяжение намагничивающихся капель не зависит от поля, а в [22] получены результаты о существенном изменении поверхностного натяжения в магнитных полях напряженностью $10 \mathrm{kA} / \mathrm{м}$ и более.

Для микрокапельных агрегатов размером 1-10мкм, которые входят в состав некоторых магнитных жидкостей, граница раздела представляет собой границу между двумя намагничивающимися жидкими средами с высокой концентрацией магнитных частиц внутри микрокапель и с низкой концентрацией у окружающей их жидкости, а величина межфазного натяжения на границе раздела на несколько порядков меньше, чем у макроскопических капель (см. [4, 23, 25]). Сложность описания гидростатики таких агрегатов связана с проблемой одновременного определения магнитных и поверхностных свойств и ограничениями применимости теории линейного намагничивания. В частности, в [12] сделан вывод о неприменимости линей теории для изучения влияния магнитного поля на межфазное натяжение намагничивающихся микрокапель в полях более $1 \mathrm{kA} / \mathrm{м}$.

Таким образом, вопрос о влиянии магнитного поля на поверхностное натяжение макроскопических намагничивающихся капель и на межфазное натяжение микрокапель нуждается в дальнейших исследованиях. Трудоемкость проведения экспериментальных исследований колебаний и 
деформации микрокапельных агрегатов ставит задачу как по автоматизации измерений, так и по разработке систем компьютерного моделирования.

1.1. Описание объекта и методов исследования. В данной работе представлены результаты вычислительного эксперимента, полученные с помощью разработанных модели и системы компьютерного моделирования вынужденных колебаний намагничивающихся микрокапель в переменном магнитном поле с учетом зависимости $\sigma(H)$.

Для определения вида $\sigma(H)$ использованы экспериментальные результаты, представленные в [20]. Для аппроксимации экспериментальных данных методом наименьших квадратов выбрана функция $f(x, a, b)=a \cdot \exp (b \cdot x)$. В результате математическая модель (см. [15]), полученная в предположении об эллипсоидальности формы и о линейном характере намагничивания микрокапель (см. [27]), дополнена уравнениями, представляющими $\sigma(H)$ при различных начальных значениях $\sigma(H)$ (см. [16]):

$$
\begin{gathered}
\frac{4 \pi R^{2}}{135}\left(\rho_{1}+\frac{\rho_{2}}{2}\right) \cdot\left[\frac{d^{2} q(t)}{d t^{2}}\left(q(t)^{-8 / 3}+2 q(t)^{-2 / 3}\right)-\frac{2}{3} \cdot\left(\left(\frac{d q(t)}{d t}\right)^{2} \cdot\left(2 q(t)^{-11 / 3}+q(t)^{-5 / 3}\right)\right)\right]+ \\
\quad+\frac{16}{9} \eta \pi q^{-2} \frac{d q(t)}{d t}+\frac{\pi \sigma(H) q^{1 / 3}}{3 R\left(q(t)^{2}-1\right)}\left(\frac{q(t)^{2}-4}{\sqrt{q(t)^{2}-1}} \arcsin \frac{\sqrt{q(t)^{2}-1}}{q(t)}+2 q(t)^{-2}+1\right)- \\
\left.\times \frac{\left[\left(\ln \left(2 q(t)^{2}+2 q(t) \sqrt{q(t)^{2}-1}-1\right)-2 \sqrt{1-q(t)^{-2}}\right) \cdot\left(2 q(t)^{2}+1\right) \cdot\left(q(t)^{2}-1\right)^{-\frac{3}{2}}-2 q(t)^{-1}\right]}{\left[q(t)\left(\frac{\mu_{i}}{\mu_{e}}-1\right) \cdot\left(\ln \left(2 q(t)^{2}+2 q(t) \sqrt{q(t)^{2}-1}-1\right)-2 \sqrt{1-q(t)^{-2}}\right)+2 \cdot\left(q(t)^{2}-1\right)^{3 / 2}\right.}\right]^{2}=0
\end{gathered}
$$

где

$$
\sigma(H)=\left\{\begin{array}{lc}
1,5 e^{5,7 \cdot 10^{-3} \cdot|H|} \cdot 10^{-7} & \text { при } 10^{-7} \leqslant \sigma(0)<10^{-6} \\
0,6 e^{1,5 \cdot 10^{-3} \cdot|H|} \cdot 10^{-5} & \text { при } 10^{-5} \leqslant \sigma(0)<10^{-4} \\
0,3 e^{0,7 \cdot 10^{-3} \cdot|H|} \cdot 10^{-4} & \text { при } 10^{-4} \leqslant \sigma(0)<10^{-3} \\
H(t)=H_{0}+H_{a} \sin (\omega t+\varphi) &
\end{array}\right.
$$

где $R, \rho_{1}, \mu_{i}$ - соответственно радиус, плотность и магнитная проницаемость высококонцентрированной магнитожидкостной микрокапли, $\rho_{2}$ и $\mu_{e}$ - соответственно плотность и магнитная проницаемость окружающей каплю слабоконцентрованной магнитной жидкости, $q(t)$ - обобщенная координата, представляющая собой отношение полуосей эллипсоида $q(t)=a(t) / b(t)$, $a(t)>b(t), d q(t) / d t$ - производная обобщенной координаты, $\eta$ - вязкость микрокапли, $\sigma(H)-$ межфазное натяжение, $\omega=2 \pi f, f, \varphi$ - частота и фаза переменного магнитного поля, $H(t)=$ $H_{0}+H_{a} \sin (\omega t+\varphi)$ - напряженность внешнего магнитного поля.

Система уравнений (1) позволяет описать динамику намагничивающихся микрокапель с учетом характера изменения $\sigma(H)$ при различных начальных значениях межфазного натяжения: $10^{-7} \mathrm{H} / \mathrm{M} \leqslant \sigma(0) \leqslant 10^{-3} \mathrm{H} / \mathrm{M}$.

Предложенная модель реализована в MATLAB и Simulink. Для разработки системы компьютерного моделирования вынужденных колебаний намагничивающейся микрокапли дифференциальное уравнение второго порядка системы уравнений (1) представлено в виде системы дифференциальных уравнений первого порядка:

$$
\frac{d V_{q}(t)}{d t}=\frac{2\left(q(t)^{2}+2\right)}{3 q(t)\left(2 q(t)^{2}+1\right)} V_{q}(t)^{2}-\frac{60 \eta(t) q(t)^{2 / 3}}{r^{2}\left(\rho_{1}+\frac{\rho_{2}}{2}\right)\left(2 q(t)^{2}+1\right)} V_{q}(t)+\frac{45 \sigma(t) q(t)^{3}}{4 r^{3}\left(\rho_{1}+\frac{\rho_{2}}{2}\right)\left(2 q(t)^{2}+1\right)\left(q(t)^{2}-1\right)} \times
$$




$$
\begin{gathered}
\times\left(\frac{q(t)^{2}-4}{\sqrt{q(t)^{2}-1}} \sin ^{-1}\left(\frac{\sqrt{q(t)^{2}-1}}{q(t)}\right)+2 q(t)^{-2}+1\right)-\frac{45 \mu_{0}\left(\mu_{i}-\mu_{e}\right)^{2} H(t)^{2}\left(q(t)^{2}-1\right)^{2}}{2 r^{2}\left(\rho_{1}+\frac{\rho_{2}}{2}\right)\left(q(t)^{-8 / 3}+2 q(t)^{-2 / 3}\right)} \times \\
\times \frac{\left[\left(\ln \left(2 q(t)^{2}+2 q(t) \sqrt{q(t)^{2}-1}-1\right)-2 \sqrt{1-q(t)^{-2}}\right) \cdot\left(2 q(t)^{2}+1\right)\left(q(t)^{2}-1\right)^{-3 / 2}-2 q(t)^{-1}\right]}{q(t)\left(\frac{\mu_{i}}{\mu_{e}}-1\right)\left(\ln \left(2 q(t)^{2}+2 q(t) \sqrt{q(t)^{2}-1}-1\right)-2 \sqrt{1-q(t)^{-2}}+2\left(q(t)^{2}-1\right)^{3 / 2}\right)^{2}}=0,
\end{gathered}
$$

где

$$
\begin{gathered}
\frac{d q(t)}{d t}=V_{q}(t), \\
\sigma(H)=\left\{\begin{array}{cc}
1,5 e^{5,7 \cdot 10^{-3} \cdot|H|} \cdot 10^{-7} & \text { при } 10^{-7} \leqslant \sigma(0)<10^{-6}, \\
0,6 e^{1,5 \cdot 10^{-3} \cdot|H|} \cdot 10^{-5} & \text { при } 10^{-5} \leqslant \sigma(0)<10^{-4}, \\
0,3 e^{0,7 \cdot 10^{-3} \cdot|H|} \cdot 10^{-4} & \text { при } 10^{-4} \leqslant \sigma(0)<10^{-3}, \\
H(t)=H_{0}+H_{a} \sin (2 \pi f t+\varphi) .
\end{array}\right.
\end{gathered}
$$

На рис. 1 представлена система компьютерного моделирования, разработанная в пакете Simulink матричной лаборатории Matlab. Эта система, в отличие от описанной ранее в [27] coдержит модуль для определения $\sigma(H)$.

Подсистема «1» содержит четыре модуля 2-5 для определения влияния сил различной природы на характер колебаний. Модуль 2 предназначен для расчета коэффициента

$$
E(q)=\frac{2\left(q(t)^{2}+2\right)}{3 q(t)\left(2 q(t)^{2}+1\right)}
$$

при $V_{q}(t)^{2}$ в первом слагаемом правой части первого дифференциального уравнения системы (2). Следующие три модуля (3-5) позволяют вычислять соответственно второе, третье и четвертое слагаемые правой части первого уравнения системы уравнений (2). Модуль 3 позволяет определить коэффициент при $V_{q}(t)^{2}$, который характеризует действие на каплю: вязких и инерционных сил $E(\eta) / E(\rho), 4$ - поверхностных и инерционных сил $E(\sigma) / E(\rho) ; 5$ - магнитных и инерционных сил $E(\mu) / E(\rho)$. Подсистема «6» предназначена для расчета напряженности внешнего магнитного поля, действующего на намагничивающуюся каплю: $H(t)=H_{0}+H_{a} \sin (\omega t+\varphi)$.

Результаты вычислений подсистемы «6» и модулей 2-5 регистрируются прибором Scope, входящим в подсистему «1». Устройства XY Graph и XY Graph 1 служат для построения фазового портрета исследуемой динамической системы, описывающей вынужденные колебания намагничивающейся капли во внешнем магнитном поле, и построения зависимости обобщенной координаты $q(t)=a(t) / b(t), a(t)>b(t)$, представляющей отношения осей эллипсоида, описывающего форму капли от напряженности внешнего магнитного поля $q(H)$.

1.2. Описание и анализ результатов. Моделирование вынужденных колебаний намагничивающихся капель в переменном магнитном поле осуществлялось в математическом пакете Mathcad на основе численного решения системы уравнений (1) и с помощью разработанной в пакетах MATLAB и Simulink системы компьютерного моделирования на основе системы уравнений (2).

На рис. 2-4 представлены полученные с помощью системы компьютерного моделирования (рис. 1) результаты вычислительного эксперимента по моделированию вынужденных колебаний микрокапли радиусом $r=5$ мкм со следующими параметрами:

$$
\rho_{1}=1900 \mathrm{\kappa г} / \mathrm{m}^{3}, \quad \rho_{2}=1060 \mathrm{Kr} / \mathrm{m}^{3}, \quad \mu=1, \quad \mu_{i}=50, \quad \sigma(0)=1,5 \cdot 10^{-7} \mathrm{H} / \mathrm{M}, \quad \eta=0,226 \Pi \mathrm{a} \cdot \mathrm{c},
$$



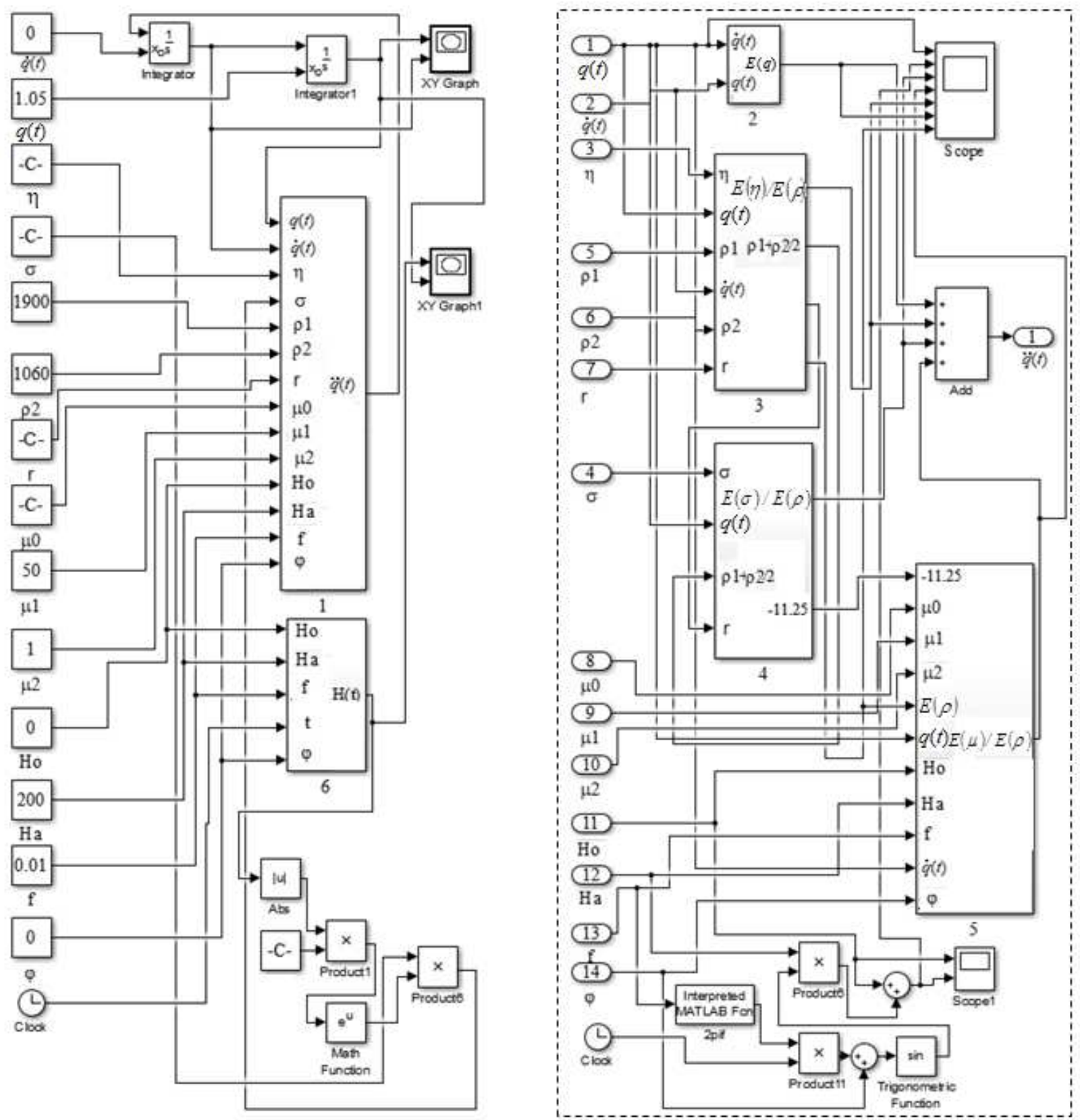

Рис. 1. Структура системы компьютерного моделирования с подсистемой «1», содержащей модули $2-5$, и подсистема «6»

под действием переменного магнитного поля с параметрами

$$
H_{0}=0, \quad H_{a}=200 \mathrm{~A} / \mathrm{M}, \quad f=0,01 \Gamma_{ц}
$$

и зарегистрированные прибором Scope.

Кривая 1 соответствует значениям $q(t)$; кривая 3 показывает характер изменения внешнего магнитного поля $H(t)$; кривыми 2,4 и 5 представлены соответственно $E(q)$ и зависимости отношений $E(\mu) / E(\rho), E(\sigma) / E(\rho)$ и $E(\eta) / E(\rho)$ от времени. Временная зависимость $q(t)$ является периодической, микрокапля успевает изменять форму в течение полупериода колебаний внешнего поля. Кривые 4, 5, 6 характеризуют влияние сил различной природы (магнитных, поверхностных и вязких) на колебательный процесс. 

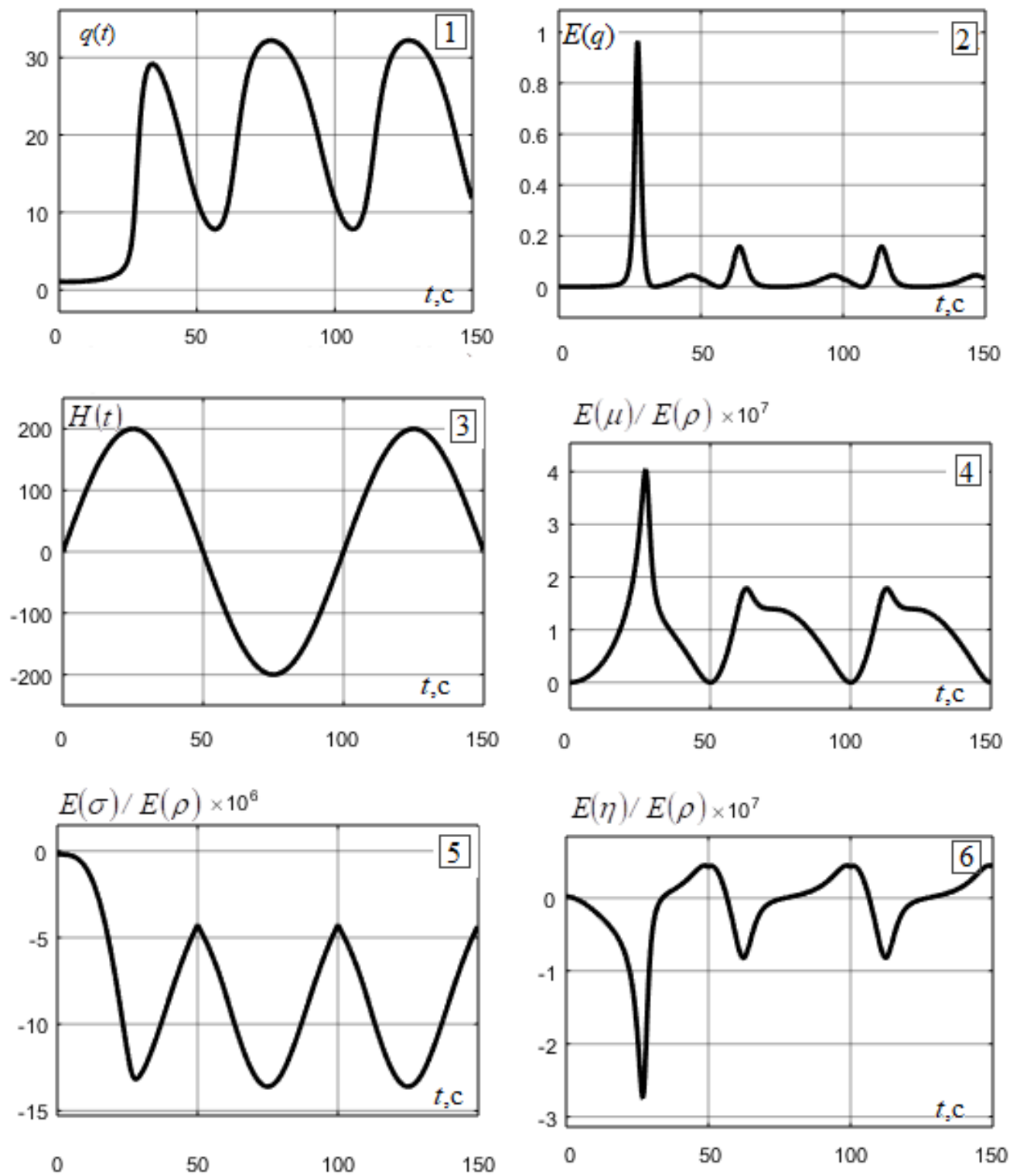

Рис. 2. Временные зависимости: $q(t)$ - кривая $1 ; E(q)$ - кривая $2 ; H(t)$ - кривая $3 ; E(\mu) / E(\rho)-$ кривая $4 ; E(\sigma) / E(\rho)$ - кривая $5 ; E(\eta) / E(\rho)$ - кривая 6 .

На рис. 3 показана зависимость мгновенных значений отношения полуосей микрокапель $q(t)$ от мгновенных значений синусоидального магнитного поля, которая регистрируется прибором XY Graph. Как видно из рис. 3, зависимость $q()$ носит гистерезисный характер, причем быстрое увеличение $q(t)$ соответствует наружным участкам графиков и возникает тогда, когда внешнее поле превышает пороговое поле скачкообразного удлинения ${ }_{1}$. При уменьшении внешнего поля изменение $q(t)$ происходит медленнее и соответствует внутренним участкам графика.

На рис. 4 приведен фазовый портрет исследуемой динамической системы, описывающей вынужденные колебания намагничивающейся капли во внешнем магнитном поле.

Из рис. 3 и 4 видно, что в установившемся режиме вынужденные колебания намагничивающихся микрокапель носят гистерезисный характер.

Сравнение результатов численного моделирования колебаний намагничивающейся микрокапли с помощью уравнений (1), (2) в системе компьютерной математики Mathcad и с помощью, 

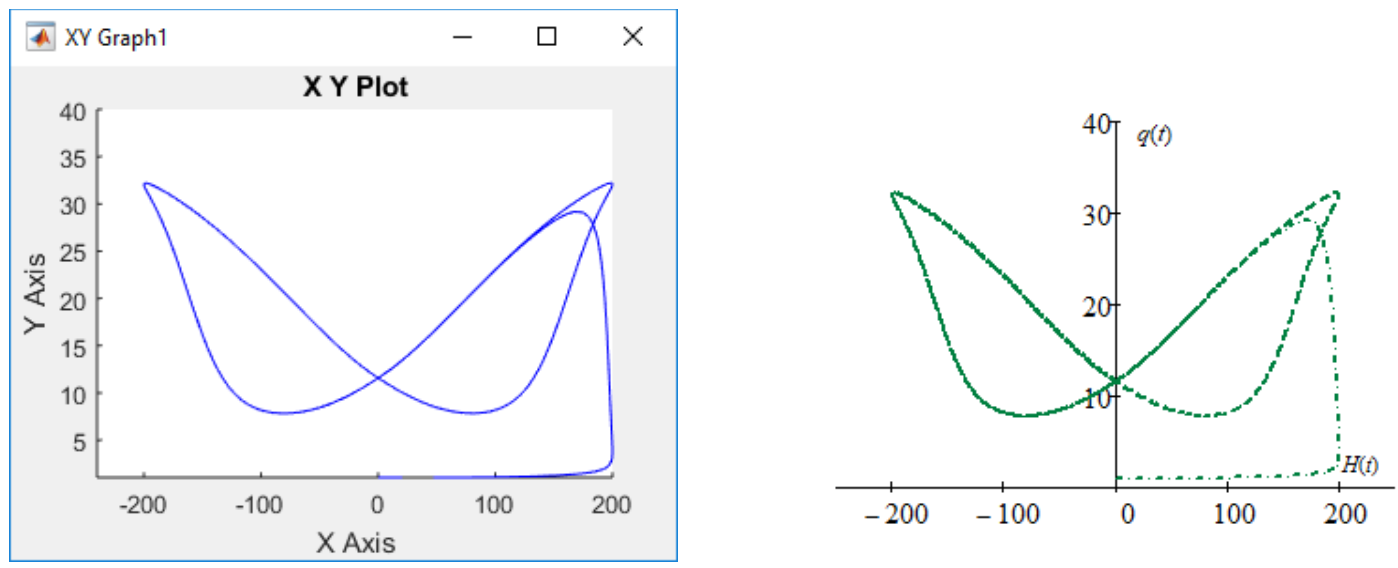

Рис. 3. Зависимость $q(H)$ при $\sigma(0)=1,5 \cdot 10^{-7} \mathrm{H} /$ м в системе Matlab (a) и в системе Mathcad (b)
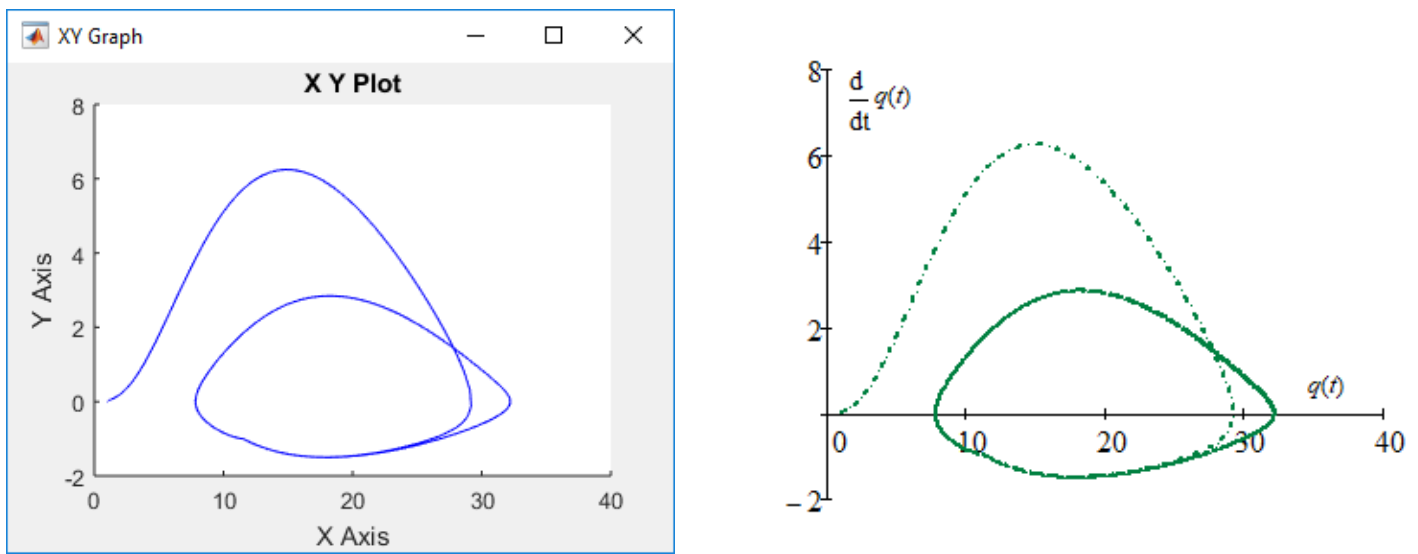

Pис. 4. Фазовый портрет в системе Matlab (a) и в системе Mathcad (b)

разработанной в пакете расширения Simulink (Matlab) системе компьютерного моделирования, основанной на системе уравнений (2) показало, что они совпадают.

Проведено сравнение результатов натурного и вычислительного экспериментов, полученных при $\sigma(0)=1,5 \cdot 10^{-7} \mathrm{H} /$ м, и установлено, что результаты моделирования согласуются с экспериментальными результатами. Колебания микрокапель при других $\sigma(0)$ экспериментально не исследовались.

1.3. Выводы. Разработанная система компьютерного моделирования позволяет проводить вычислительный эксперимент по моделированию вынужденных колебаний намагничивающиеся микрокапель на основе зависимостей межфазного натяжения от напряженности внешнего магнитного поля, полученных по данным натурного эксперимента. Результаты моделирования согласуются с экспериментальными результатами и могут быть полезны при разработке устройств, в которых используются магнитные жидкости, содержащие намагничивающиеся микрокапли.

\section{СПИСОК ЛИТЕРАТУРЫ}

1. Дроздова В. И., Скибин Ю. Н., Шагрова Г. В., Якштас А. А. Способ определения полей рассеяния магнитных головок/ Авторское свидетельство № 1465843. - 1989.

2. Дроздова В. И., Скибин Ю. Н., Шагрова Г. В., Шульга О. В., Якштас А. А. Магниточувствительная жидкость для визуализации магнитной записи/ Авторское свидетельство № 1593484. - 1990. 
3. Братухин Ю. К., Лебедев А. В. Вынужденные колебания капли магнитной жидкости// ЖЭТФ. 2002. - 121, № 6. - С. 1298-1305.

4. Гладких Д. В., Диканский Ю. И. Особенности взаимодействия магнитной жидкости, имеющей микрокапельную структуру, с переменным магнитным полем// Ж. техн. физ. -2006 . -26 , № 8. - С. 13-18.

5. Голубятников A. Н., Субханкулов Г. И. О поверхностном натяжении магнитной жидкости// Магнит. гидродинам. -1986 . - № 1. - С. 73-78.

6. Директор Л. Б., Майков И. Л. К задаче определения теплофизических свойств жидкости методом незатухающих колебаний капли// XIX Междунар. конф. «Уравнения состояния вещества» (Эльбрус, 11-17 марта 2004 г.). - Нальчик, 2004. - С. 21-22.

7. Дроздова В. И., Кушнарев В. В., Шагрова Г. В. О вынужденных колебаний микрокапельных агрегатов в магнитных жидкостях// Коллоид. ж. - 2006. - 68, № 2. - С. 1-6.

8. Дроздова В. И., Скибин Ю. Н., Чеканов В. В. Исследование колебаний капель магнитной жидкости// Магнит. гидродинам. - 1981. - № 4. - С. 17-23.

9. Жакин А. И. О зависимости поверхностного натяжения растворов и суспензий от напряженности магнитного и электрического полей// Магнит. гидродинам. - 1989. - № 3. - С. 75-80.

10. Жаров А. Н., Ширяева С. О., Григорьев А. И. Нелинейные колебания заряженной капли в третьем порядке малости по амплитуде многомодовой начальной деформации// Ж. техн. физ. $-2003 .-73$, № 12. - C. 9-19.

11. Жуков $A$. В. Влияние электромагнитного поля на поверхностное натяжение и устойчивость поверхностей раздела поляризующихся и намагничивающихся жидкостей// Вестн. Нижегород. ун-та им. Н. И. Лобачевского. Мех. жидк. газа. - 2011. - 4, № 3. - С. 781-783.

12. Иванов А. С., Хохрякова (Бушуева) K. А. О линейной теории зависимости поверхностного межфазного натяжения капельных агрегатов в магнитных жидкостях// VI Bсеросс. науч. конф. «Физико-химические и прикладные проблемы магнитных дисперсных наносистем» (Ставрополь, сентябрь 2017 г.). - Ставрополь: СКФУ, 2017. - С. 312-318.

13. Майков И. Л., Директор Л. Б. Численная модель динамики капли вязкой жидкости// Вычисл. мет. программир. - 2009. - 10. - С. 148-157.

14. Майков И. Л., Директор Л. Б. Численное решение задачи о затухающих нелинейных колебаниях капли вязкой жидкости// ЖЭТФ. - 2008. - 133, № 6. - С. 1-8.

15. Романенко М. Г., Дроздова В. И., Шагрова Г. В. Моделирование колебаний магнитожидкостных микрокапель с учетом зависимостей вязкости и поверхностного натяжения от температуры// Междунар. науч. конф. «Актуальные проблемы прикладной математики и физики» (Нальчик-Терскол, 17-21 мая 2017 г.). - Нальчик: ИПМА КБНЦ РАН, 2017. - С. 265.

16. Романенко М. Г., Шагрова Г. В., Дроздова В. И. Моделирование колебаний магнитожидкостных микрокапель с учетом зависимости поверхностного натяжения от поля// IV Междунар. науч. конф. «Актуальные проблемы прикладной математики» (Нальчик-Терскол, 22-26 мая 2018 г.). - Нальчик: ИПМА КБНЦ РАН, 2018. - С. 216.

17. Рэлей Д. Теория звука. - М.: Гостехиздат, 1944.

18. Цеберс А. О. Образование и свойства крупных конгломератов магнитных частиц// Магнит. гидродинам. $-1983 .-19$, № $3 .-$ С. $3-11$.

19. Чеканов В. В., Халуповский М. Д., Чуенкова И. Ю., Малютин В. В. О форме капли и межфазном натяжении магнитной жидкости в однородном магнитном поле// Магнит. гидродинам. $-1988 .-24$, № 3. - С. $124-128$.

20. Шагрова Г. В., Дроздова В. И., Романенко М. Г. Экспериментальное исследование зависимости межфазного натяжения магнитожидкостных микрокапель от магнитного поля// VI Всеросс. науч. конф. «Физико-химические и прикладные проблемы магнитных дисперсных наносистем» (Ставрополь, 6-9 сентября 2017 г.). - Ставрополь: СКФУ, 2017. - С. 96-102.

21. Шагрова Г. В., Дроздова В. И., Терехин В. И., Романенко М. Г. Применение магнитных жидкостей в дефектоскопии// Междунар. конф. «Современные методы и средства неразрушающего контроля и технической диагностики» (Ялта, 3-7 октября 2005). - Киев, 2005. - С. 141-143.

22. Afkhami S., Tyler A. J., Renardy Y., Renardy M., St. Pierre T. G., Woodward R. C., Riffle J. S. Deformation of a hydrophobic ferrouid droplet suspended in a viscous medium under uniform magnetic fields// J. Fluid Mech. - 2010. - 663. - P. 358-384. 
23. Bacri J. C., Salin D. Dynamics of the shape transition of a magnetic ferrofluid drop// J. Phys. Lett. 1983. - 44. - P. 415-420.

24. Bzdek B. R., Power R. M., Simpson S. H., Reid J. P., Roya C. P. Precise, contactless measurements of the surface tension of picolitre aerosol droplets// Chem Sci. — 2016. - 7, № 1. - P. 274-285.

25. Drozdova V. I., Shagrova G. V. Dynamics of optical scattering on ferrofluid agglomerate magnetic drops// J. Magnet. Magnet. Mater. - 1990. — 85. - P. 93-96.

26. Paradis P. F., Ishikawa T., Yoda Noncontact measurements of surface tension and viscosity of Niobium, Zirconium, and Titanium using an electrostatic levitation furnace// Int. J. Thermophys. - 2002. — 23, № 3. - P. 825-842.

27. Shagrova G. V., Drozdova V. I., Romanenko M. G. Modeling oscillations of magnetizable microdrops/ 04020-1, 04020-4 J. Nano Electron. Phys. — 2015. — 7, № 4.

Романенко Марина Геннадьевна

Северо-Кавказский федеральный университет, Ставрополь

Шагрова Галина Вячеславовна

Северо-Кавказский федеральный университет, Ставрополь

E-mail: shagrovagv@mail.ru

Дроздова Виктория Игоревна

Северо-Кавказский федеральный университет, Ставрополь

E-mail: ist@stv.runnet.ru 